\title{
Effect of Size, Shape, and Surface Modification on Cytotoxicity of Gold Nanoparticles to Human HEp-2 and Canine MDCK Cells
}

\author{
Yinan Zhang, ${ }^{1}$ Dan $\mathrm{Xu},{ }^{2,3}$ Wenqin Li, ${ }^{1,2}$ Jun $\mathrm{Yu}^{2}$ and Yu Chen ${ }^{1}$ \\ ${ }^{1}$ Department of Physics, University of Strathclyde, John Anderson Building, 107 Rotternrow, Glasgow G4 ONG, UK \\ ${ }^{2}$ Strathclyde Institute of Pharmacy and Biomedical Sciences, University of Strathclyde, Glasgow G4 ORE, UK \\ ${ }^{3}$ Institute of Immunopathology, School of Life Science \& Technology, Xi' an Jiaotong University, Shanxi 710061, China
}

Correspondence should be addressed to Yu Chen, y.chen@strath.ac.uk

Received 25 March 2012; Revised 20 April 2012; Accepted 23 April 2012

Academic Editor: Grégory Guisbiers

Copyright (C) 2012 Yinan Zhang et al. This is an open access article distributed under the Creative Commons Attribution License, which permits unrestricted use, distribution, and reproduction in any medium, provided the original work is properly cited.

\begin{abstract}
There have been increasing interests in applying gold nanoparticles in biological research, drug delivery, and therapy. As the interaction of gold nanoparticles with cells relies on properties of nanoparticles, the cytotoxicity is complex and still under debating. In this work, we investigate the cytotoxicity of gold nanoparticles of different encapsulations, surface charge states, sizes and shapes to both human HEp-2 and canine MDCK cells. We found that cetyltrimethylammonium-bromide- (CTAB-) encapsulated gold nanorods (GNRs) were relatively higher cytotoxic than GNRs undergone further polymer coating and citrate stabilized gold nanospheres (GNSs). The toxicity of CTAB-encapsulated GNRs was mainly caused by CTAB on GNRs' surface but not free CTAB in the solution. No obvious difference was found among GNRs of different aspect ratios. Time-lapse study revealed that cell death caused by GNRs occurred predominately within one hour through apoptosis, whereas cell death by free CTAB was in a time- and dose-dependent manner. Both positively and negatively surface-charged polymer-coated GNRs (PSS-GNRs and PAH-PSS-GNRs) showed similar levels of cytotoxic, suggesting the significance of surface functionality rather than surface charge in this case.
\end{abstract}

\section{Introduction}

Gold nanoparticles have been demonstrated to have extraordinary potential in biomedical applications including biological imaging, sensing, thermal therapy, drug and gene delivery [1-11]. Compared to gold nanospheres (GNSs), gold nanorods (GNRs) are especially beneficial in biological imaging and sensing due to their unique optical properties [12-14]. Cytotoxicity of gold nanoparticles, as the premise of any further biological study, is a key issue to be investigated. There have been intensive studies from different point of views focusing on the cytotoxicity of gold nanoparticles, which are complex and still under debating. Compared to GNSs, GNRs have been found to be toxic to cell culture, but almost nontoxic after being coated with polymer molecules $[10,15-27]$. This is because the cytotoxicity depends on the particle size, shape, surface charge and modification, agglomeration, as well as the mechanisms of cellular uptake and toxicity response [28-30]. Despite difference in particle shape, one primary concerns about GNRs in biological research is cetyltrimethylammonium bromide (CTAB), the surfactant which is essential for nanorods growth in popularly used seed-growth GNRs synthesis method, but toxic to cell lines [26, 31-33]. CTAB is important in controlling the particle size and shape to achieve designed localized surface plasmon resonance bands for spectroscopic and microscopic applications in biological research [34-36]. As removal of CTAB will cause instability of GNRs, polymers, such as poly(acrylic acid) (PAA), poly(diallyldimethylammonium chloride)-poly(4-styrenesulfonic acid) (PDADMAC-PSS), and poly(ethylene glycol) (PEG), have been introduced to functionalize the GNRs surface $[31,32,37,38]$.

Optical properties of gold nanoparticles critically depend on their sizes, shapes, and surface conditions. On the other hand, incubation time and particle concentration are key parameters in controlling the internalization process of nanoparticles into cells, as well as cell normal functions. In this paper, we intended to investigate the cytotoxicity 


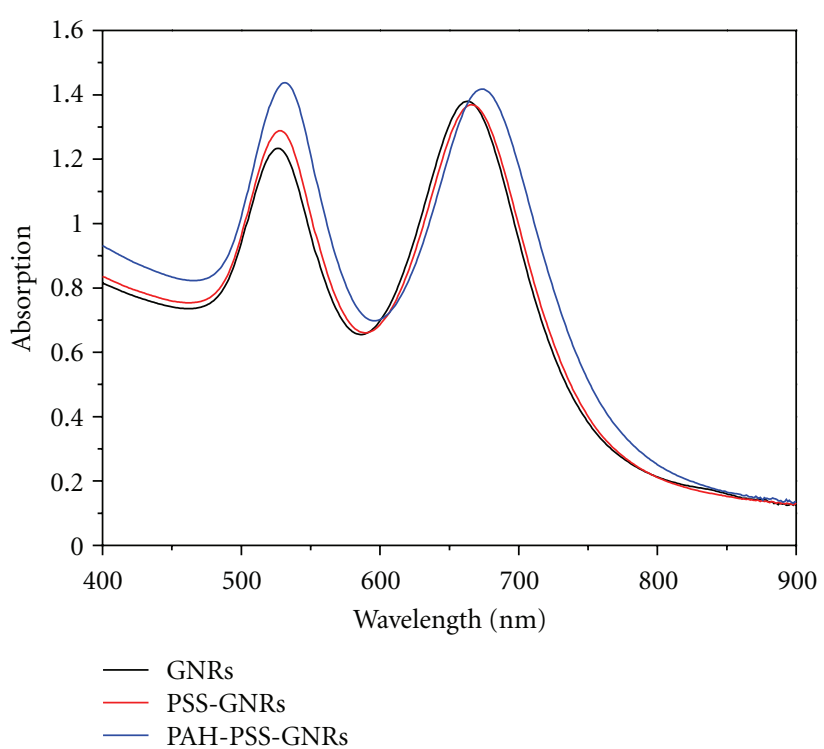

(a)

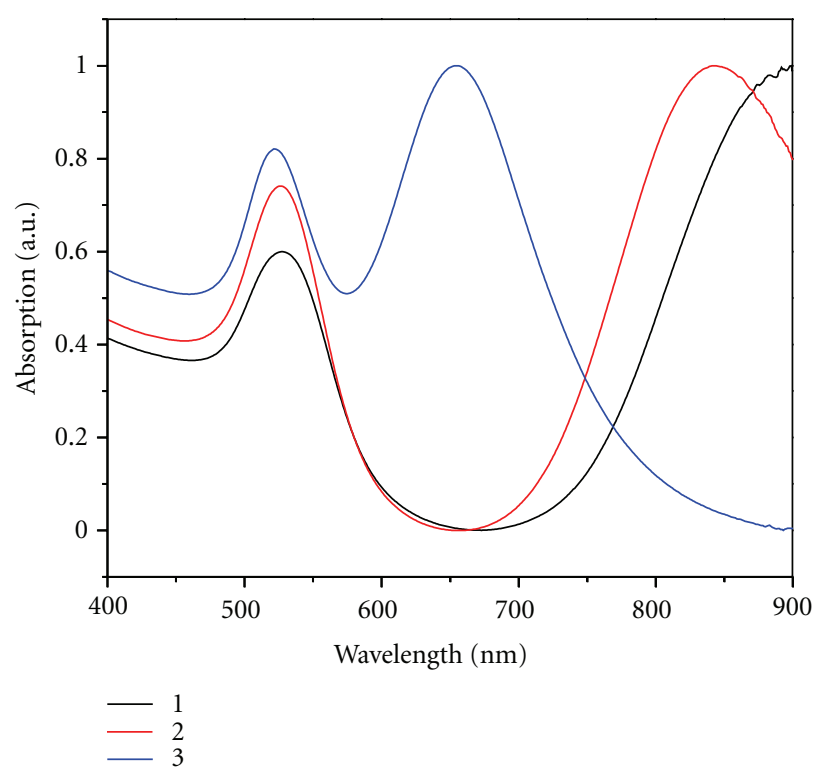

(b)

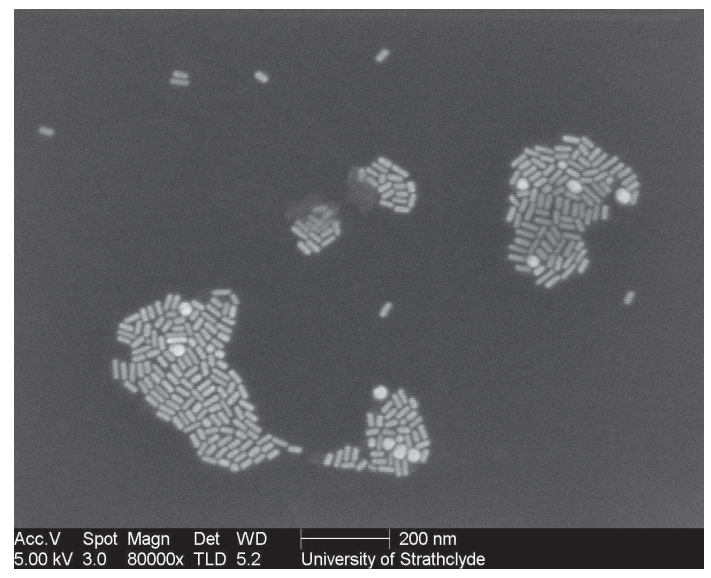

(c)

Figure 1: (a) Absorption spectrum of GNRs and polymer-coated GNRs; (b) absorption spectrum of GNR-1, GNR-2, and GNR-3; (c) scanning electron microscopic image of GNR-1.

of gold nanoparticles in a systematic manner. GNRs were synthesized via the same procedure but with 4 different aspect ratios, GNSs, and polymer- (polystryrenesulfonate (PSS) and poly(allylamine) hydrochloride(PAH)) coated GNRs have been applied to two cell lines at different exposure time and particle dosages. GNRs of aspect ratio of 3 are approximately $40 \mathrm{~nm}$ long, which had excellent potential in biological imaging and sensing applications [39-41]. PSS and PAH have been used in multilayer membrane for longterm graft transplantation [42]. The layer-by-layer polyelectrolyte coating using PSS/PAH not only changes the surface condition of gold particles inducing changes in particle optical properties but also plays important roles in functionalizing new types of bioimaging tools, such as SPASER (surface plasmon amplification by stimulated emission of radiation), a surface-plasmon-based nanolaser providing localized intensive excitation [43-45]. The dosage levels and incubation time selected for 3-(4,5-Dimethylthiazol-2-yl)2,5-diphenyltetrazolium bromide MTT assay analysis was based on the previous imaging study $[39,41]$. In addition to reveal the intrinsic cytotoxicity of gold nanoparticles, this study also provide insights on managing the cytotoxicity of gold nanoparticles in further biological research.

\section{Material and Method}

GNRs were synthesized by the seeded growth method [46], and GNSs were prepared by Turkevich method [47]. Further coating on GNRs was proceeded via electrostatic layer-bylayer growth using PSS and PAH. Single layer of PSS and double layers of PSS/PAH coating were carried out following a process described by Omura et al. (denoted as PSS-GNRs and PAH-PSS-GNRs) [45]. Successful coating is proven by 
the shift of surface plasmon bands as shown in Figure 1(a). All particles were centrifuged to remove the excess $\mathrm{CTAB} /$ polymers and redispersed in deionised water with a final concentration around $10^{-10} \mathrm{M}$.

MDCK (ATCC CCL-34) and HEp-2 (ATCC CCL-23) cell lines were obtained from American Type Culture Collection. Cell culture medium was high-glucose (4.5 g/L) DMEM containing fetal calf serum (10\%), L-glutamine $(2.9 \mathrm{mg} / \mathrm{mL})$, antibiotic-antimycotic solution (GIBCO). Cells were routinely cultured at $37^{\circ} \mathrm{C}$ under $5 \% \mathrm{CO}_{2}$.

MTT assay was carried out in the following procedure. Briefly, both MDCK and HEp-2 cells were seeded at $1 \times$ $10^{4}$ cells per well in 96-well plates. After $24 \mathrm{~h}$ of incubation $\left(37^{\circ} \mathrm{C}, 5 \% \mathrm{CO}_{2}\right)$, a series of concentrations of GNRs (in water) was added in each well. The cells were further incubated to appropriate time intervals. At appropriate time intervals, $20 \mu \mathrm{L}$ of MTT (3-(4,5-Dimethylthiazol-2-yl)-2,5diphenyltetrazolium bromide, $4 \mathrm{mg} / \mathrm{mL}$ in PBS) was added to each well and incubated for up to $4 \mathrm{~h}$ at $37^{\circ} \mathrm{C}, 5 \% \mathrm{CO}_{2}$. After careful removal of the media, $150 \mu \mathrm{L}$ of DMSO was added into each well to solubilise the purple crystals. After being incubated at $37^{\circ} \mathrm{C}$ for $10 \mathrm{~min}, \mathrm{OD}_{540 \mathrm{~nm}}$ was measured with a plate reader (LabSystems Genesis).

For fluorescent microscopic observation of apoptosis, cells were seeded onto cover slides $1 \times 10^{5}$ cells per slide in 24-well plates and cultured for $24 \mathrm{~h}$ at $37^{\circ} \mathrm{C}$ under $5 \%$ $\mathrm{CO}_{2}$. After exposure to GNRs for $5 \mathrm{~h}$, the spent medium was discarded and cells were incubated for $1 \mathrm{~h}$ in fresh media containing sulforhodaminyl-L-valylalanylaspartyl fluoromethyl ketone (SR-VA-DFMK) according to manufacturer's instructions (Immunochemistry Technologies). Cells were washed with PBS and fixed with 3.7\% paraformaldehyde (in PBS) for $10 \mathrm{~min}$ at $37^{\circ} \mathrm{C}$. The coverslips were mounted onto microscope slides with Prolong Gold antifade reagent containing $4^{\prime}, 6^{\prime}$-diamidino-2-phenylindole (DAPI) (Invitrogen). Images were captured using a confocal microscope LSM 510 (Carl Zeiss).

\section{Results and Discussion}

Figure 1(a) displays absorption spectra taken from GNRs, PSS-GNRs, and PAH-PSS-GNRs. Absorption of three GRNs of different aspect ratios, 5, 4.5, and 3, are shown in Figure 1(b), where a typical SEM image of GNR-1 is displayed in Figure 1(c). Figure 2 shows the MTT assay results on HEp-2 cells incubated for $1 \mathrm{~h}$ with different types of gold nanoparticles. The dosage is calculated as the volume percentage of cell medium, for gold particles, concentration of $1 \%$ is approximately $10^{-12} \mathrm{M}$. Contribution in absorption from gold nanoparticles in MTT assay has been subtracted taking into account the absorption coefficient of different gold nanoparticles at $540 \mathrm{~nm}$ and number of nanoparticles in cell culture.

Based on results displayed in Figure 2, GNRs have shown much higher toxicity compared to GNSs. The (Citrate stabilized) GNSs showed no significant cytotoxicity under all dosage levels used, while for CTAB-capped GNRs, high cytotoxicity was found especially at large dosages. It cannot

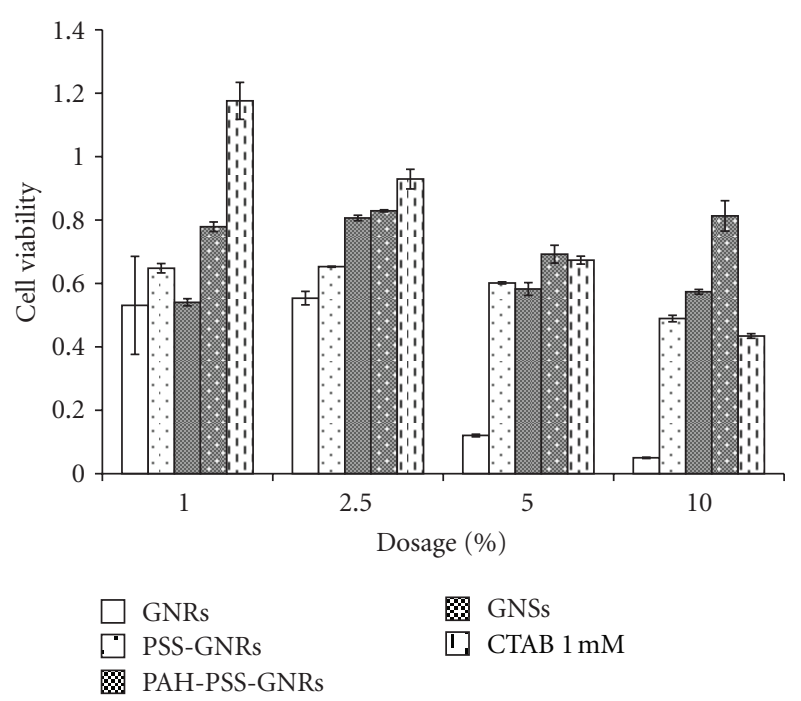

FIGURE 2: Cytotoxicity of different types of gold particles and free CTAB based on MTT assay outlined above.

be simply explained as shape effect, as GNSs and GNRs have different surfactants and surface charge states. To elucidate the effects from capped CTAB, polymer-coated GNRs have been compared with CTAB capped GNRs. Figure 2 shows that both PSS-GNRs and PAH-PSS-GNRs are less toxic than GNRs, which becomes more apparent at higher dosages.

The above observation is in line with the previous finding that $\mathrm{CTAB}$ is the major reason for cytotoxicity [31, 32]. Nevertheless, the cause of the cytotoxicity, either the free CTAB in solution or surfactant ones, is still debatable. To bring insights into this issue, toxicity of free CTAB to Hep2 was examined. Figure 2 shows that free CTAB solution is less toxic than $C T A B$ capped GNRs. We thus propose that the toxicity of GNRs is mainly related to the surface CTAB on GNRs rather than free form in the solution based on three facts. Firstly, as polymer-coated GNRs were centrifuged under the same condition as GNRs, concentration of free $\mathrm{CTAB}$ in the solution can be considered at a similar level. Therefore, the different cytotoxic properties should be originated from different surface conditions. Secondly, $1 \mathrm{mM}$ of CTAB used here is $1 \%$ of the concentration used for GNRs synthesis and considered to be the upper limit of remaining CTAB in GNRs solution after centrifuge. This is because GNRs solution was diluted roughly 10 times after each centrifugation and concentration of free CTAB is below $1 / 100$ of the original concentration after two times of centrifugations. Figure 2 shows that $1 \mathrm{mM} \mathrm{CTAB}$ has only moderate cytotoxicity, much lower than GNRs, implying that toxicity of GNRs is not mainly due to free CTAB. This result is consistent with that of the time-lapse toxicity shown in Figure 3(b), as cell survival of samples treated with $1 \mathrm{mM}$ CTAB solution from $1 \%$ to $10 \%$ of medium volume (actual concentration $1 \times 10^{-5} \mathrm{M}$ to $1 \times 10^{-4} \mathrm{M}$ ) decreased from more than $90 \%$ to around $60 \%$. At last, time-lapse toxicity study reveals different cytotoxic behaviour between GRNs and free 


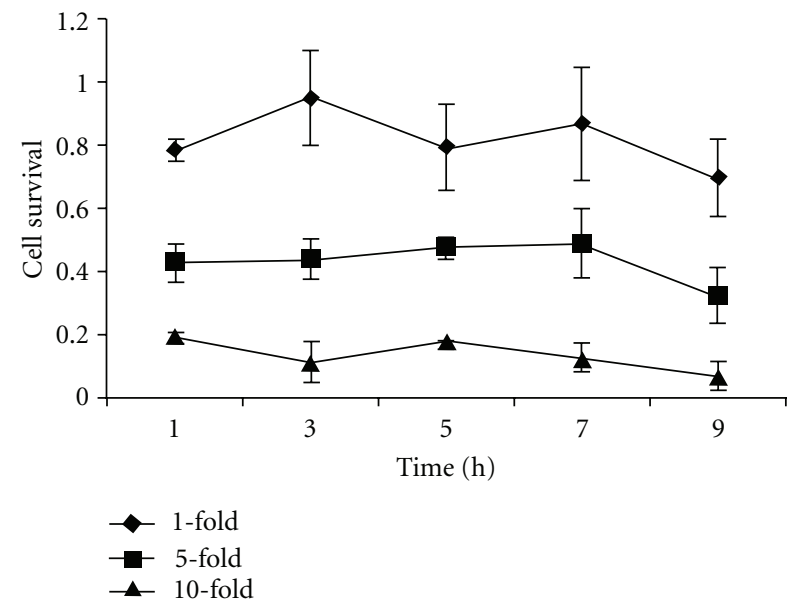

(a)

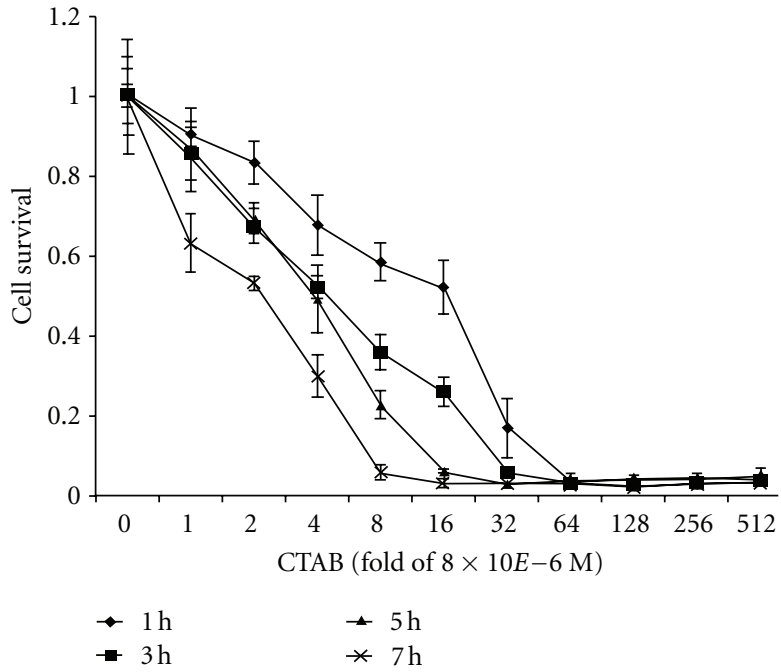

(b)

Figure 3: Time lapse cytotoxicity of GNRs (a) and free CTAB (b) to HEp-2, $1 \mathrm{~h}, 3 \mathrm{~h}, 5 \mathrm{~h}$, and $7 \mathrm{~h}$ indicate different incubation times, and 1 -fold of $8 \times 10^{-6} \mathrm{M}$ CTAB is comparable to the $1 \%$ concentration in the form of volume concentration in Figure 2.

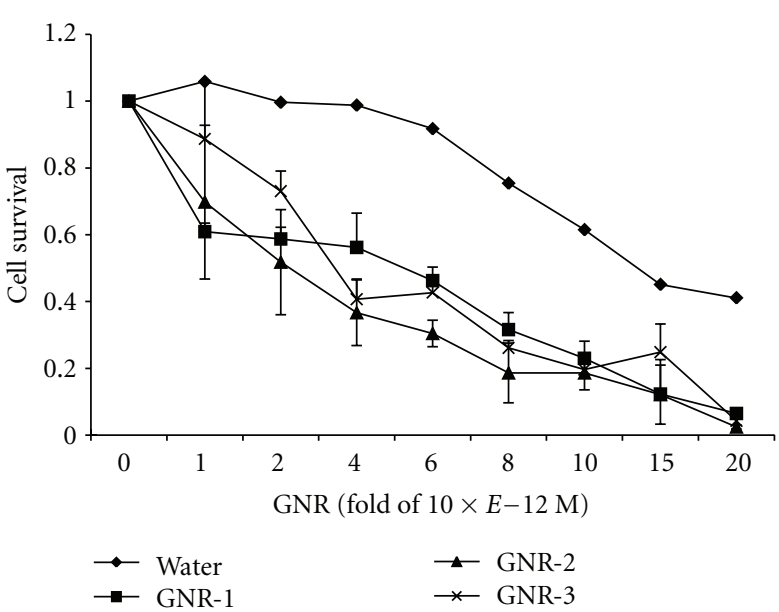

(a)

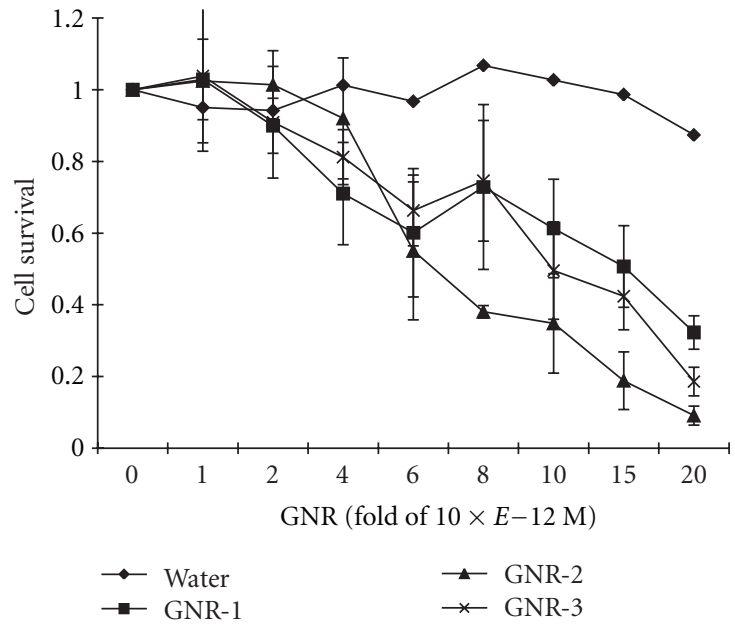

(b)

Figure 4: MTT assay for HEp-2 (a) and MDCK (b) cells.

CTAB. Figure 3(a) shows that cell survival value reaches a stable number in the first hour, and further incubation only results in slight reduction in cell survival up to $9 \mathrm{hrs}$. While by incubating a series of concentrations of free CTAB solution to the cells for 1, 3, 5, and 7 hours, a dependence on both concentration and incubation time was observed in Figure 3(b).

Additional polymer coating of GNRs not only prevents direct interaction of CTAB with cell membrane but also modifies the surface charge state. Previous work suggests that cationic gold particles are moderately toxic, whereas anionic ones are relatively nontoxic $[25,48]$. This phenomenon can be explained as the cell membrane is negatively charged in which case cationic particles are prone to adsorb. Furthermore, it has also been reported that cationic particles are more likely to follow a direct diffusion pathway while anionic GNPs are internalized by endocytosis [25, 49]. In this work, negatively charged PSS-GNRs perform less toxic on all dosages, and no significant difference was observed between PSS-GNRs and positively charged PAH-PSS-GNRs. Considering both PAH-PSS-GNRs and GNRs have positive surface charge, the discrepancy in cytotoxicity between CTAB capped and polymer-coated GNRs should be related to the surface CTAB on GNRs. With GNRs sizing around $50 \mathrm{~nm}$, surface modification and interaction with membrane functional parts may play a more important role than surface charge property.

To study the influence of size and shape on the cytotoxicity, GNRs of different aspect ratios were examined. It is found that all three types of GNRs exhibited cytotoxicity to both MDCK and HEp-2 cells in a dose-dependent manner as shown in Figures 4(a) and 4(b), but no significant 

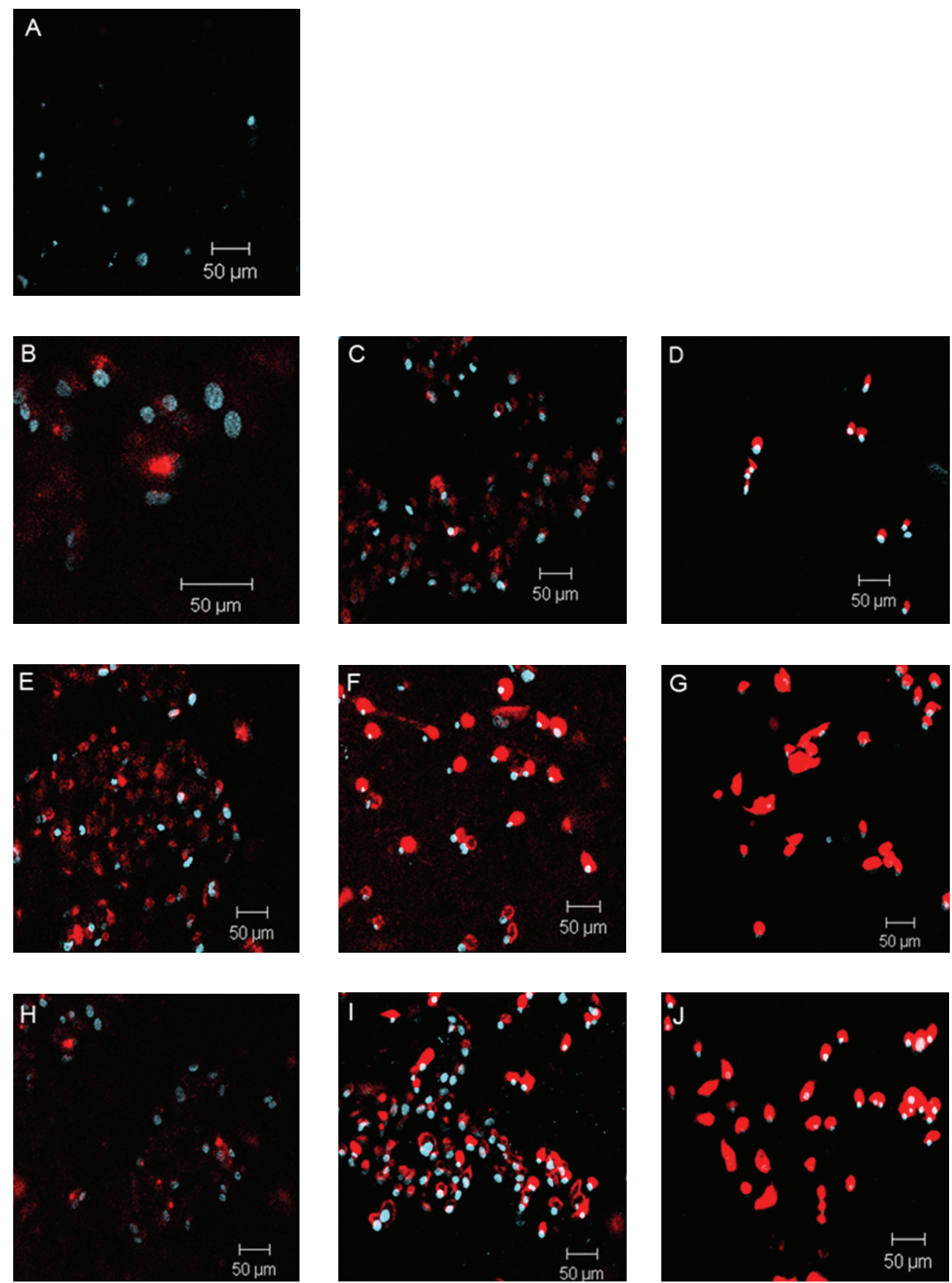

Figure 5: Confocal microscopy on HEp-2 cells for activated caspases (in red) and nuclei (in blue). All images were taken $5 \mathrm{~h}$ after GNR treatment. (A) negative control (untreated cells); (B), (C), and (D), respectively, were cells treated with GNR-1 at the concentration of 1-, 5and 10 -fold of $10^{-12} \mathrm{M}$ of stock solution. Similarly, (E), (F), and (G) were cells treated with GNR-2, and (H), (I), (J) were cells treated with GNR-3, respectively, at the concentrations of 1-, 5-, and 10-fold of the $10^{-12} \mathrm{M}$ solutions.

difference were found between GNRs. The viability of the cells decreased as the concentrations of GNRs increased. However, the two cell lines had significant difference in susceptibility to GNR-1 and GNR-2 at 2-fold of $10^{-12} \mathrm{M}$ (Student $t$-test, $P<0.1$ in both cases): viability of HEp2 cells dropped below $60 \%$, whereas MDCK cells remained above $90 \%$ in both cases. Based on gold particle concentration and cell counts, we estimated that at $10^{-12} \mathrm{M}$ GNRs concentration, the particle cell ratio is approximately 300 GNRs per cell, which reduced cell viability by $\sim 20 \%$ in all cases and may be used as an upper limit reference for cellular research.

To detect apoptosis, cells were stained with SR-VADFMK, which detect all activated caspases. The activation of caspases can be quantitatively correlated with the intensity of the fluorescent intensity. All three types of GNRs were 
confirmed to induce the activation of caspases in both cell lines with different capacity as is shown in Figure 5. In general, the accumulation of activated caspases depends on the dosage of GNRs, which is in accordance with the MTT assay. Even at low dosage, activated caspases were detected in HEp-2 cells. The signal intensity increased with the rising dosage, and in the cases of treatment with high dose (10fold of $10^{-12} \mathrm{M}$ ), all cells were all stained strongly and many cells were detached at this stage. All these results suggest that GNRs have triggered apoptotic process. For MDCK cells, figures not shown here, a similar trend has been observed, while the stain was relatively weaker compared to Hep- 2 cells and did not increase as drastically as HEp-2 cells when higher concentrations of GNRs applied, which is in accordance with the MTT assay results.

In conclusion, GNRs show relative higher cytotoxicity compared to GNSs and PSS/PAH-coated GNRs to HEp-2 cells, which is mainly related to the CTAB on particle surface rather than the free ones in solution. Furthermore, dosage rather than time scale is more important in GNRs-induced cytotoxicity. The majority cell death occurs within one hour of incubation via GNRs-induced apoptosis processes. Change in the aspect ratio up to 5 has little influence on GNRs' cytotoxicity. Additional polymer (PSS/PAH) coating can significantly improve cell survival, which seems not due to the change of surface charge properties but isolation of $\mathrm{CTAB}$ from cell membrane by additional layer(s) of barrier.

\section{Acknowledgments}

This work was supported by an EPSRC Science and Innovation Award and a Pump Priming Award from SPIBS University of Strathclyde. D. Xu was supported by a Ph.D. mobility program from the Chinese Government. The authors also thank Alison McLintock and Dr. Alastair Ward for their support on GNSs synthesis. The authors do not have a direct financial relation with the commercial identity mentioned in the paper that might lead to a conflict of interests for any of the authors.

\section{References}

[1] P. K. Jain, I. H. ElSayed, and M. A. El-Sayed, "Au nanoparticles target cancer," Nano Today, vol. 2, no. 1, pp. 18-29, 2007.

[2] X. Liu, Q. Dai, L. Austin et al., "A one-step homogeneous immunoassay for cancer biomarker detection using gold nanoparticle probes coupled with dynamic light scattering," Journal of the American Chemical Society, vol. 130, no. 9, pp. 2780-2782, 2008.

[3] C. Yu and J. Irudayaraj, "Multiplex biosensor using gold nanorods," Analytical Chemistry, vol. 79, no. 2, pp. 572-579, 2007.

[4] A. K. Salem, P. C. Searson, and K. W. Leong, "Multifunctional nanorods for gene delivery," Nature Materials, vol. 2, no. 10, pp. 668-671, 2003.

[5] C. C. Chen, Y. P. Lin, C. W. Wang et al., "DNA-gold nanorod conjugates for remote control of localized gene expression by near infrared irradiation," Journal of the American Chemical Society, vol. 128, no. 11, pp. 3709-3715, 2006.
[6] N. J. Durr, T. Larson, D. K. Smith, B. A. Korgel, K. Sokolov, and A. Ben-Yakar, "Two-photon luminescence imaging of cancer cells using molecularly targeted gold nanorods," Nano Letters, vol. 7, no. 4, pp. 941-945, 2007.

[7] K. Imura, T. Nagahara, and H. Okamoto, "Near-field optical imaging of plasmon modes in gold nanorods," Journal of Chemical Physics, vol. 122, no. 15, Article ID 154701, pp. 15, 2005.

[8] K. Imura, T. Nagahara, and H. Okamoto, "Near-field two-photon-induced photoluminescence from single gold nanorods and imaging of plasmon modes," Journal of Physical Chemistry B, vol. 109, no. 27, pp. 13214-13220, 2005.

[9] P. K. Jain, X. Huang, I. H. El-Sayed, and M. A. El-Sayed, "Noble metals on the nanoscale: optical and photothermal properties and some applications in imaging, sensing, biology, and medicine," Accounts of Chemical Research, vol. 41, no. 12, pp. 1578-1586, 2008.

[10] C. J. Murphy, A. M. Gole, J. W. Stone et al., "Gold nanoparticles in biology: beyond toxicity to cellular imaging," Accounts of Chemical Research, vol. 41, no. 12, pp. 1721-1730, 2008.

[11] X. Huang, I. H. El-Sayed, W. Qian, and M. A. El-Sayed, "Cancer cell imaging and photothermal therapy in the nearinfrared region by using gold nanorods," Journal of the American Chemical Society, vol. 128, no. 6, pp. 2115-2120, 2006.

[12] K. S. Lee and M. A. El-Sayed, "Gold and silver nanoparticles in sensing and imaging: sensitivity of plasmon response to size, shape, and metal composition," Journal of Physical Chemistry B, vol. 110, no. 39, pp. 19220-19225, 2006.

[13] P. K. Jain, K. S. Lee, I. H. El-Sayed, and M. A. ElSayed, "Calculated absorption and scattering properties of gold nanoparticles of different size, shape, and composition: applications in biological imaging and biomedicine," Journal of Physical Chemistry B, vol. 110, no. 14, pp. 7238-7248, 2006.

[14] H. Wang, T. B. Huff, D. A. Zweifel et al., "In vitro and in vivo two-photon luminescence imaging of single gold nanorods," Proceedings of the National Academy of Sciences of the United States of America, vol. 102, no. 44, pp. 15752-15756, 2005.

[15] N. Lewinski, V. Colvin, and R. Drezek, "Cytotoxicity of nanopartides," Small, vol. 4, no. 1, pp. 26-49, 2008.

[16] H. J. Johnston, G. Hutchison, F. M. Christensen, S. Peters, S. Hankin, and V. Stone, "A review of the in vivo and in vitro toxicity of silver and gold particulates: particle attributes and biological mechanisms responsible for the observed toxicity," Critical Reviews in Toxicology, vol. 40, no. 4, pp. 328-346, 2010.

[17] M. Thomas and A. M. Klibanov, "Conjugation to gold nanoparticles enhances polyethylenimine's transfer of plasmid dna into mammalian cells," Proceedings of the National Academy of Sciences of the United States of America, vol. 100, no. 16, pp. 9138-9143, 2003.

[18] N. L. Rosi, D. A. Giljohann, C. S. Thaxton, A. K. R. LyttonJean, M. S. Han, and C. A. Mirkin, "Oligonucleotide-modified gold nanoparticles for infracellular gene regulation," Science, vol. 312, no. 5776, pp. 1027-1030, 2006.

[19] B. D. Chithrani and W. C. W. Chan, "Elucidating the mechanism of cellular uptake and removal of protein-coated gold nanoparticles of different sizes and shapes," Nano Letters, vol. 7, no. 6, pp. 1542-1550, 2007.

[20] Y. Pan, S. Neuss, A. Leifert et al., "Size-dependent cytotoxicity of gold nanoparticles," Small, vol. 3, no. 11, pp. 1941-1949, 2007.

[21] E. Boisselier and D. Astruc, "Gold nanoparticles in nanomedicine: preparations, imaging, diagnostics, therapies and 
toxicity," Chemical Society Reviews, vol. 38, no. 6, pp. 17591782, 2009.

[22] X. Huang, P. K. Jain, I. H. El-Sayed, and M. A. El-Sayed, "Gold nanoparticles: interesting optical properties and recent applications in cancer diagnostics and therapy," Nanomedicine, vol. 2, no. 5, pp. 681-693, 2007.

[23] W. Cui, J. Li, Y. Zhang, H. Rong, W. Lu, and L. Jiang, "Effects of aggregation and the surface properties of gold nanoparticles on cytotoxicity and cell growth," Nanomedicine, vol. 8 , no. 1 , pp. 46-53, 2012.

[24] Y. Hao, X. Yang, S. Song et al., "Exploring the cell uptake mechanism of phospholipid and polyethylene glycol coated gold nanoparticles," Nanotechnology, vol. 23, no. 4, Article ID 045103, 2012.

[25] X. M. Jiang, L. M. Wang, and C. Y. Chen, "Cellular uptake, intracellular trafficking and biological responses of gold nanoparticles," Journal of the Chinese Chemical Society, vol. 58, no. 3, pp. 273-281, 2011.

[26] Y. Qiu, Y. Liu, L. Wang et al., "Surface chemistry and aspect ratio mediated cellular uptake of Au nanorods," Biomaterials, vol. 31, no. 30, pp. 7606-7619, 2010.

[27] N. M. Schaeublin, L. K. Braydich-Stolle, E. I. Maurer et al., "Does shape matter? Bioeffects of gold nanomaterials in a human skin cell model," Langmuir, vol. 28, no. 6, pp. 32483258, 2012.

[28] B. Nikoobakht and M. A. El-Sayed, "Preparation and growth mechanism of gold nanorods (NRs) using seed-mediated growth method," Chemistry of Materials, vol. 15, no. 10, pp. 1957-1962, 2003.

[29] C. J. Johnson, E. Dujardin, S. A. Davis, C. J. Murphy, and S. Mann, "Growth and form of gold nanorods prepared by seedmediated, surfactant-directed synthesis," Journal of Materials Chemistry, vol. 12, no. 6, pp. 1765-1770, 2002.

[30] N. R. Jana, L. Gearheart, and C. J. Murphy, "Wet chemical synthesis of high aspect ratio cylindrical gold nanorods," Journal of Physical Chemistry B, vol. 105, no. 19, pp. 40654067, 2001.

[31] S. Wang, W. Lu, O. Tovmachenko, U. S. Rai, H. Yu, and P. C. Ray, "Challenge in understanding size and shape dependent toxicity of gold nanomaterials in human skin keratinocytes," Chemical Physics Letters, vol. 463, no. 1-3, pp. 145-149, 2008.

[32] A. M. Alkilany, P. K. Nagaria, C. R. Hexel, T. J. Shaw, C. J. Murphy, and M. D. Wyatt, "Cellular uptake and cytotoxicity of gold nanorods: molecular origin of cytotoxicity and surface effects," Small, vol. 5, no. 6, pp. 701-708, 2009.

[33] T. Niidome, M. Yamagata, Y. Okamoto et al., "PEG-modified gold nanorods with a stealth character for in vivo applications," Journal of Controlled Release, vol. 114, no. 3, pp. 343347, 2006.

[34] D. Mirska, K. Schirmer, S. S. Funari, A. Langner, B. Dobner, and G. Brezesinski, "Biophysical and biochemical properties of a binary lipid mixture for DNA transfection," Colloids and Surfaces B, vol. 40, no. 1, pp. 51-59, 2005.

[35] H. Takahashi, Y. Niidome, T. Niidome, K. Kaneko, H. Kawasaki, and S. Yamada, "Modification of gold nanorods using phosphatidylcholine to reduce cytotoxicity," Langmuir, vol. 22, no. 1, pp. 2-5, 2006.

[36] E. E. Connor, J. Mwamuka, A. Gole, C. J. Murphy, and M. D. Wyatt, "Gold nanoparticles are taken up by human cells but do not cause acute cytotoxicity," Small, vol. 1, no. 3, pp. 325-327, 2005.

[37] S. C. Boca and S. Astilean, "Detoxification of gold nanorods by conjugation with thiolated poly(ethylene glycol) and their assessment as SERS-active carriers of Raman tags," Nanotechnology, vol. 21, no. 23, Article ID 235601, 2010.

[38] C. Grabinski, N. Schaeublin, A. Wijaya et al., "Effect of gold nanorod surface chemistry on cellular response," ACS Nano, vol. 5, no. 4, pp. 2870-2879, 2011.

[39] Y. Zhang, J. Yu, D. J. Birch, and Y. Chen, "Gold nanorods for fluorescence lifetime imaging in biology," Journal of Biomedical Optics, vol. 15, no. 2, p. 020504-3, 2010.

[40] Y. Zhang, J. Yu, D. J. S. Birch, and Y. Chen, "Gold nanorods for applications in biological imaging," in Proceedings of the SPIE, January 2011.

[41] Y. Zhang, D. J. S. Birch, and Y. Chen, "Two-photon excited surface plasmon enhanced energy transfer between DAPI and gold nanoparticles: opportunities in intra-cellular imaging and sensing," Applied Physics Letters, vol. 99, no. 10, Article ID 103701, 2011.

[42] A. Leung, M. Trau, and L. K. Nielsen, "Assembly of multilayer PSS/PAH membrane on coherent alginate/PLO microcapsule for long-term graft transplantation," Journal of Biomedical Materials Research A, vol. 88, no. 1, pp. 226-237, 2009.

[43] D. J. Bergman and M. I. Stockman, "Surface plasmon amplification by stimulated emission of radiation: quantum generation of coherent surface plasmons in nanosystems," Physical Review Letters, vol. 90, no. 2, pp. 027402/1-027402/4, 2003.

[44] M. A. Noginov, G. Zhu, A. M. Belgrave et al., "Demonstration of a spaser-based nanolaser," Nature, vol. 460, no. 7259, pp. 1110-1112, 2009.

[45] N. Omura, I. Uechi, and S. Yamada, "Comparison of plasmonic sensing between polymer-and silica-coated gold nanorods," Analytical Sciences, vol. 25, no. 2, pp. 255-259, 2009.

[46] C. J. Murphy, T. K. Sau, A. M. Gole et al., "Anisotropic metal nanoparticles: synthesis, assembly, and optical applications," Journal of Physical Chemistry B, vol. 109, no. 29, pp. 1385713870, 2005.

[47] J. Kimling, M. Maier, B. Okenve, V. Kotaidis, H. Ballot, and A. Plech, "Turkevich method for gold nanoparticle synthesis revisited," Journal of Physical Chemistry B, vol. 110, no. 32, pp. 15700-15707, 2006.

[48] C. M. Goodman, C. D. McCusker, T. Yilmaz, and V. M. Rotello, "Toxicity of gold nanoparticles functionalized with cationic and anionic side chains," Bioconjugate Chemistry, vol. 15, no. 4, pp. 897-900, 2004.

[49] J. Lin, H. Zhang, Z. Chen, and Y. Zheng, "Penetration of lipid membranes by gold nanoparticles: insights into cellular uptake, cytotoxicity, and their relationship," ACS Nano, vol. 4, no. 9, pp. 5421-5429, 2010. 

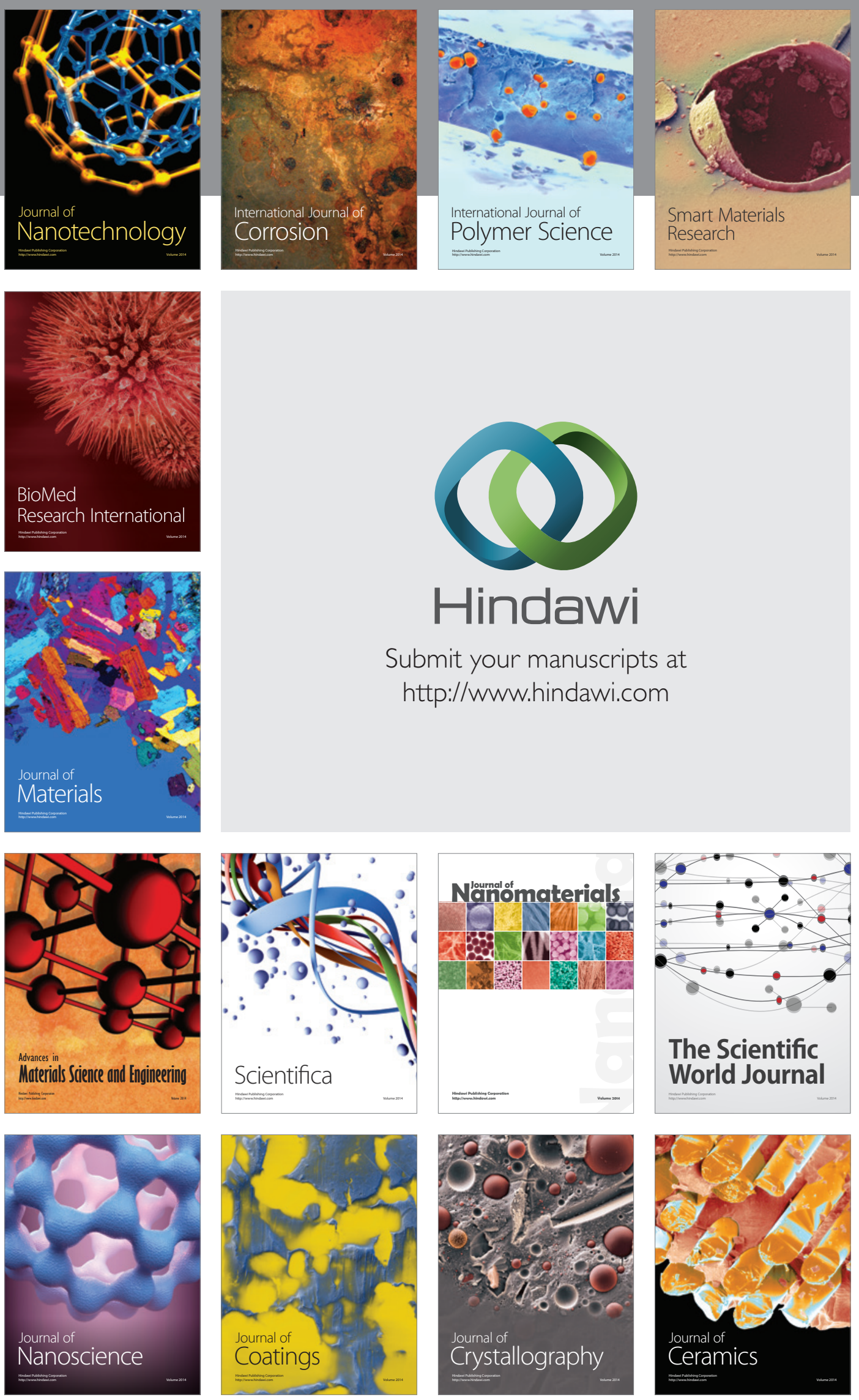

The Scientific World Journal

Submit your manuscripts at

http://www.hindawi.com

\section{World Journal}

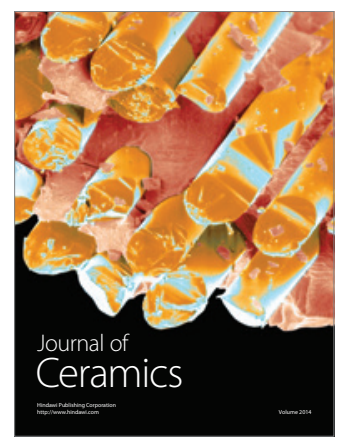

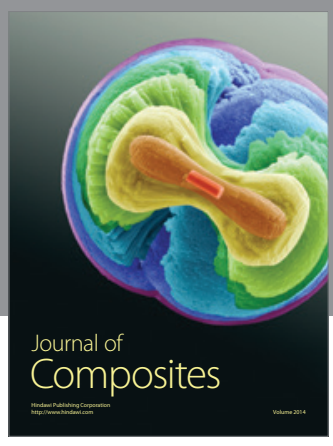
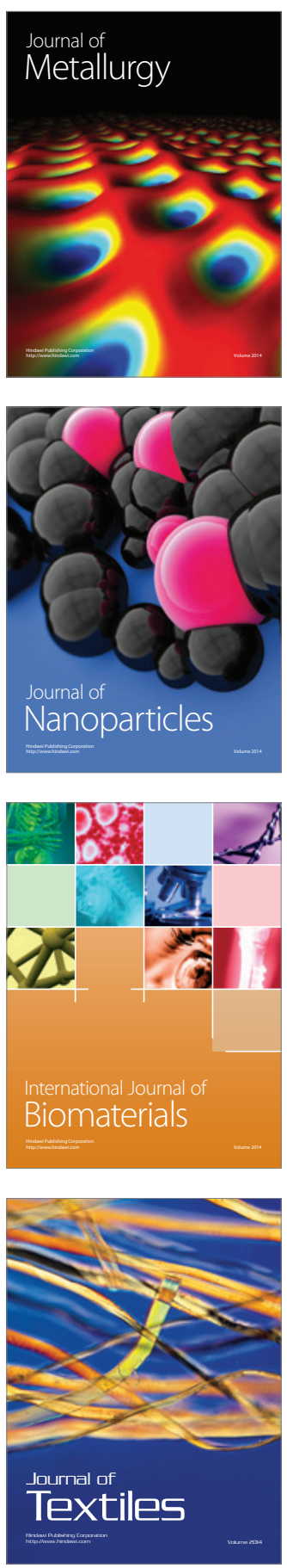